\title{
¿POR QUÉ NO ES UNA TRAGEDIA LA ROMA ABRASADA DE LOPE DE VEGA? (SOBRE PARALITERATURA Y PARODIA EN LOPE)
}

\author{
Enrique Jesús Rodríguez Baltanás
}

El propósito de estas líneas es el de continuar y completar lo que de modo general expusimos en otro trabajo nuestro, «Literatura y paraliteratura en el teatro de Lope de Vega: hacia un nuevo deslinde en la producción dramática del Fénix» ${ }^{1}$, a la luz de cuyos resultados profundizamos ahora en el análisis de una obra concreta. Aspiramos a demostrar por qué Roma abrasada no es una tragedia - con las conclusiones que de ello se derivan-, a pesar de lo que algún sector de la crítica actual parece sostener ${ }^{2} \mathrm{y}$, sobre todo, a pesar de que su autor mismo, Lope de Vega, la subtitulase de ese modo e insistiera en la adscripción genérica en la dedicatoria de la obra al cronista D. Gil González de Ávila: «a deuda que lo es tanto, paga mi corto caudal con la Tragedia de Roma, no en su grandeza [...] sino abrasada...» ${ }^{3}$. Sin embargo es realmente imposible que podamos considerar tragedia a tal pieza, aunque así la denominara el propio Lope, como vamos a ver enseguida a través de una atenta lectura del desarrollo de su acción dramática.

1 En Revista de Literatura, t. L, núm. 99, 1988, pp. 37-60.

2 Así, por ejemplo, en D. Moir y E. M. Wilson, Siglos de Oro: teatro (1492-1700), Barcelona, Ariel, 1979, leemos que la Roma abrasada es una «tragedia interesante y vigorosa» (p. 105). También E. S. Morby parece aceptar sin discusión el marbete de Lope y describe Roma abrasada como una «Lope's earliest tragedia» («Some observations on tragedia and tragicomedia in Lope», en Hispanic Review, XI, 1943, núm. 3, p. 203).

3 Citamos por Obras de Lope de Vega. XV, Comedias históricas y de asunto extranjero, Ed. y est. prel. de D. Marcelino Menéndez Pelayo, Madrid, Atlas, 1966 (B.A.E., t. CXCI), pp. 61-122. 


\section{La jornada primera.}

Comienza la acción todavía en el reinado de Claudio, precisamente en el momento en que este ordena la expulsión de Roma de judíos y cristianos. Tras esto, Félix, uno de sus ayudantes, le informa de la licenciosa vida que lleva su esposa Mesalina, hasta el punto de haberse casado con otro en ausencia del emperador. Como si tal cosa fuese lo más natural y común del mundo, Claudio ordena su muerte. Y se torna a conversar con sus cortesanos y a pedir más información sobre los cristianos. Se dispone a comer y hace llamar a Mesalina, su esposa, a la que ha mandado matar hace un momento. El siguiente diálogo es representativo del tono por el que va a discurrir la obra:

\begin{tabular}{ll} 
FÉLIX & \multicolumn{1}{c}{ ¿No mandaste } \\
& $\begin{array}{l}\text { matarla, y el adulterio } \\
\text { con su muerte castigaste? }\end{array}$ \\
CLAUDIO & ¿Que es muerta? \\
FÉLIX & \multicolumn{1}{c}{ ¿Del vituperio } \\
& ¿Habrán to olvidaste? \\
& $\begin{array}{l}\text { de tan gran descuido y olvido? } \\
\text { Cues si es muerta, no la llames, }\end{array}$ \\
& $\begin{array}{l}\text { Pagó sus obras infames; } \\
\text { castigo del cielo ha sido. }\end{array}$ \\
& Voyme a comer.
\end{tabular}

(p. 70)

La sobrina de Claudio, Agripina, y su hijo Nerón, acuden a palacio a ver al emperador y plantearle cierto pleito. Van Agripina y Palante a hablar a Claudio, que está comiendo, y quedan solos en escena Félix y Nerón. Este momento lo aprovecha Lope para insertar, en boca de Félix, la relación de cómo llegó Claudio al poder tras la muerte de Calígula. Vuelve Palante y les da una noticia sorprendente: Claudio acaba de tomar por esposa a Agripina.

$\begin{array}{ll}\text { NERÓN } & \begin{array}{l}\text { Pues, ¡cómo! ¡Con su sobrina?... } \\ \text { No puede eso en Roma ser } \\ \text { por ley humana y divina. } \\ \text { PALANTE }\end{array} \\ & \begin{array}{l}\text { Verdad que entre los romanos } \\ \text { pero, por tocar sus manos, } \\ \text { ha hecho agora una ley } \\ \text { que casa hasta los hermanos. }\end{array}\end{array}$

En la siguiente escena aparece Séneca en diálogo con Otón. La presencia del filósofo cordobés le sirve a Lope para incorporar un laus Hispaniae en tercetos encadenados que debió de gustar al público castizo del corral de comedias ${ }^{4}$ :

4 Karl Alfred Blüher, en un sólido trabajo sobre «Lope de Vega y Séneca: A propósito de la tragedia Roma abrasada) (en prensa en Studia in honorem Prof. M. de Riquer, III, Barcelona, Edicions 
OTÓN SÉNECA
¿Que es tan hermosa España?

Es admirable, es de Europa, sin duda, la más bella; su cielo, benignísimo y afable;

y no porque soy nacido en ella te la encarezco, Otón, porque sin duda, si fuera extraño, esto dijera della.

Es su gente feroz, sabia y aguda; que es notable de España la agudeza: tan firme, que jamás su intento muda.

No es tanta como Italia su grandeza; pero tiene grandezas que la encumbran por su espaciosa y fértil aspereza.

Sus hombres más las armas acostumbran que no las letras porque las de Roma desnudas siempre en su cerviz relumbran.

La grande sierra Oróspeda la doma; el monte de Idubeda no descansa hasta que al mar su blanca arena toma.

Es tierra fértil, que jamás se cansa en producir sustento, plata y oro; y más donde a Pirene el agua amansa.

Tiene ríos que llevan un tesoro entre las guijas de diverso jaspe, y montes más famosos que Peloro.

De Ilerda a Doris, de Híspalis a Caspe, hay cosas prodigiosas, $\mathrm{y}$ riquezas como no las ha visto el indio Hidaspe.

(pp. 74-75)

Tras la boda de Claudio y Agripina, muy poco tarda ésta en rogar al Emperador que nombre a Nerón por heredero. Explica la recién desposada que, siendo Británico hijo de una adúltera, pocas certezas hay de que pueda ser hijo de Claudio:

Adopta y prohija

a mi Domicio Nerón, y cásale con tu hija, para que con esta unión uno y otro a Roma rija,

Tu sangre y la mía ansí gozarán de tu imperio.

dels Qaderns Crema) señala con acierto que este laus Hispaniae no estaba en la fuente que sigue Lope, es decir, en la Historia Imperial y Cesárea de Pedro de Mexía, ni tiene nada que ver con el tema de la pieza, por lo que su inclusión obedece al buen conocimiento que de su público tiene el autor madrileño. Escribe el profesor Blüher (cuya gentileza al enviarnos una fotocopia de su artículo en prensa agradecemos muy de veras): «Lope ha hecho suyo aquí un lugar común bien conocido y apreciado por el público de entonces, y lo ha llevado a escena de una forma especialmente eficaz poniéndolo en boca de Séneca». 
Y así lo hace Claudio quien, dirigiéndose a Nerón, exclama: «Dale esos brazos a Otavia,/ que hoy eres mi sucesor».

Viene a continuación una brevísima escena en que Séneca, en diálogo con Otón, anuncia que va a hacer una consulta a los astros sobre el futuro de Nerón. Sigue una escena, no menos breve que la anterior, en la que aparecen «Volgesio, Dardanio, soldados armenios y partos, con banderas y cajas» -imaginemos el efecto de esta aparición sobre el público del corral-, anunciando que se rebelan contra Roma.

Tras esto, salen a las tablas Séneca y Agripina. Aquel comunica a ésta lo que ha resultado de la consulta a los astros: si Nerón sube al poder, matará a su propia madre. La respuesta de la madre:

Esa ciencia [la astrología] es disparate;

y cuando no fuera error,

tenga un hijo emperador,

que yo huelgo que me mate.

(p. 79)

Y le dice a Séneca que vaya a llamarlo. Así lo hace y aparece Nerón, diciendo: «El veneno traigo aquí,/ si para eso me llamas». Trae, en efecto, un veneno. Pero no para matar a su madre, sino a su padre adoptivo, Claudio, en complicidad con Agripina, y así abrir paso a su reinado. Madre e hijo traman el compló y acuden a la siguiente estratagema para que Claudio ingiera el tósigo:

AGRIPINA

Pues escucha; este glotón

ansí ejercita la boca, que a vómitos se provoca, que es una infame invención.

Para esto, por la garganta, se mete una pluma, y luego sale de aquel vientre ciego bebida y comida tanta.

En esta pluma podremos poner el veneno.

Tras el paréntesis de una corta escena en que Palante, Félix y Otón charlan sobre el amor en los hombre viejos («Es viejo esposo de mujer gallarda,/ que paga en obras lo que falta en gustos», sentencia Otón de Claudio) y comentan una naumaquia que se acaba de celebrar, surge Agripina en las tablas y comunica a los presentes la noticia de la muerte del Emperador. Tras ella aparece Nerón, que queda reconocido y proclamado Rey de Roma:

PALANTE

FÉLIX

OTÓN

\begin{abstract}
¡Nerón, César augusto! ¡Nerón, vítor! ¡Nerón, la posesión del mundo toma! ¡Nerón invicto, Emperador de Roma!
\end{abstract}

$\mathrm{Y}$ con estos gritos concluye el primer acto de esta tragedia que, por lo que vamos viendo, poco tiene de tal. 


\section{La jornada segunda.}

Ya Emperador, Nerón comienza su reinado dando extraordinarias muestras de prudencia, piedad y mesura. Los rebeldes han sido vencidos y uno de ellos, Dardanio, que ha sido hecho prisionero, recibe el perdón del nuevo Emperador:

Tu prisión parece exceso en la piedad que procuro.

No conviene a nuestro imperio usar mal de la victoria, ni tener en cautiverio. Basta el honor de la gloria; la venganza es vituperio.

A tu tierra libre parte, que es infamia aprisionarte, de mi poder imperial; que si no fueres leal, Roma sabrá castigarte.

Nuevas pruebas de liberalidad y largueza: a los pretorianos, que «ayuda de costa piden», ordena repartirles diez talentos:

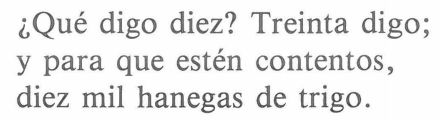

A las provincias, que se quejan de los altos y pesados tributos: «Moderénse desde hoy más, / y paguen un tercio menos». Pregunta si hay algún senador que sea pobre, y, al ser informado de que hay varios, ordena que se les den rentas del fisco. Cuando le presentan una sentencia de muerte para la firma, exclama: «¡Pluguiera a Júpiter santo/ que no supiera escribir». Finalmente llega su madre, Agripina, a pedirle unos favores para unos protegidos suyos. Ni que decir tiene que se los concede. Tantos ejemplos de bondad hacen exclamar a su preceptor, Séneca: «¿Qué más humildad buscáis?/ Roma con razón te adora».

Al fin queda solo Nerón, junto con su confidente —entreverado de alcahueteOtón, y revela su auténtica personalidad:

De hoy más seré diferente; que cinco años he vivido recogido injustamente...

Que es como decir: «hasta ahora me he visto obligado a portarme como si fuese bueno, y a partir de ahora voy a ser malo, malísimo». Y esto de improviso, sin que razón alguna, objetiva o subjetiva, medie o, al menos, tal cosa se explique en el decurso de la obra. Por lo pronto, Nerón se va de picos pardos, de juerga nocturna, a despecho de los celos de su esposa, Otavia, a la cual no ha pasado inadvertida la mudanza en el carácter y conducta observadas en Nerón: 
Anda, Palante; que tiene muy nueva la condición. Ya sale, ya se detiene, ya, contra su inclinación a la media noche viene.

Ya no ocupa tantas horas con Séneca, ya le deja; y cuando viene a deshoras, si estima en algo mi queja, es con palabras traidoras.

Ya da vueltas en la cama, ya no sosiega ni duerme, ya lo que es lícito infama; señales de aborrecerme o de que tiene otra dama.

Ya, si requiebros le digo, que se duerme me responde; si está despierto, y prosigo que por qué el rostro me esconde, me dice que le persigo.

No dudes que no es quien era.

(ibíd.)

Sigue ahora la escena de la juerga nocturna de Nerón, una de las más divertidas y por este concepto notables del drama. Es sin duda un cuadro de costumbres contemporáneas... contemporáneas de Lope, claro está, y para uso y consumo del público madrileño del seiscientos, poco escrupuloso en cuanto a detectar o rechazar anacronismos. La acotación reza: «Nerón, Niceto, Fenicio y Otón, de noche, con rodelas y capotillos; unos músicos, un hombre dentro». Véase, como muestra del tono general, el comienzo:

\begin{tabular}{|c|c|}
\hline UNO (dentro) & $\begin{array}{l}\text { Aguarden los bellacones, } \\
\text { aguarden. }\end{array}$ \\
\hline NERÓN & El diablo aguarde, \\
\hline NICETO & Bien se hizo. \\
\hline FENICIO & Llegué tarde. \\
\hline NICETO & ¡Brava fruta! \\
\hline OTÓN & Es canelones. \\
\hline NERÓN & $\begin{array}{l}\text { ¡Hermosamente corrí } \\
\text { el papel de confitura! }\end{array}$ \\
\hline OTÓN & $\begin{array}{l}\text { ¿A que buena coyuntura } \\
\text { el cintarazo le di! }\end{array}$ \\
\hline FENICIO & $\begin{array}{l}\text { Vuestra Alteza, ivive Apolo, } \\
\text { que corre como una cebra! }\end{array}$ \\
\hline NERÓN & $\begin{array}{l}\text { Ya la cabeza me quiebra } \\
\text { tanto Alteza estando solo, } \\
\quad \text { Aquí no hay Alteza agora; } \\
\text { el Cesar quédese allá; } \\
\text { que por dicha dormirá }\end{array}$ \\
\hline
\end{tabular}


con su enfadosa señora.

Cinco años de emperador

NICETO

NERÓN

OTÓN

NERÓN

OTÓN

NERÓN

OTÓN

NERÓN no estimo en lo que esta noche.

Allí suena un coche.

¿Coche?

Será de algún senador.

Si es de damas, parte, Otón,

y diles dos picardías.

Creo que son vecinas mías.

¿Quién?

Las de Mario Pisón.

¡Oh, qué feas! Tirarélas

cuatro pelladas de lodo.

Y todo va de este jaez, haciendo Nerón una completa exhibición de gamberrismo nocturno.

En la escena siguiente, Agripina comenta con Palante la depravada conducta de su hijo, y maquina favorecer a Británico, para que tema perder el poder y así vuelva a su conducta primera. Pero cuando Nerón se percata de ello, no duda en dar la orden de envenenar al inocente Británico. A partir de ahora, la comedia no es sino la relación in crescendo de las maldades de Nerón.

La siguiente es librarse de Otón, de cuya mujer, Popea, se ha enamorado. El remedio que maquina es digno de ser tan depravado: enviar al marido incómodo, hasta ahora su amigo y confidente, bien lejos de Roma, a Lusitania. Y por si fuera poco con estas acciones, hace Nerón ahora pública protestación de su maldad:

Tiemble mi madre y Otavia,
tiemble el mundo, tiemble el cielo.
.........................................
¿Quién me puede gobernar,
que a cielo ni tierra temo?
................................
Ha estado
Nerón hasta aquí dormido;
ya es tiempo de despertar.

(p. 97-98)

Y nueva crueldad: expulsa a su madre de palacio y le retira la guardia de alemanes que hasta entonces la había custodiado. Acude Agripina a su presencia y se le insinúa en monstruosa invitación al incesto. Pero Nerón la rechaza: busca ya la ocasión de deshacerse de ella. Le llega, entre tanto, recado de Popea: concederá a Nerón los favores que le requiere si, repudiada Otavia, se casa con ella.

Con la acusación - falsa, por supuesto- de haber querido matar al Emperador, condena Nerón a su madre. Esta hace su última petición:

Que la primera herida

me deis en este vientre, que éste ha sido 
causa de que Nerón saliese al mundo;

y la segunda en este pecho, en éste, que alguna vez le dio su leche y sangre.

(p. 102)

Y cuando su última voluntad es aceptada: «Pues ya muero,/ contenta en que lo pague quien lo debe». Pero la traca final de este acto viene ahora. Aparece Palante, y Nerón le espeta:

\begin{tabular}{|c|c|}
\hline & 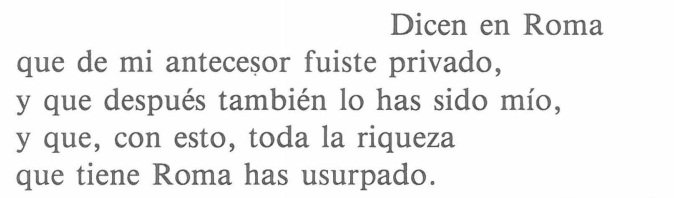 \\
\hline PALANTE & Muy pobre estoy. \\
\hline NERÓN & $\begin{array}{l}\text { Llevalde y dalde muerte, } \\
\text { y traedme el tesoro de su casa, } \\
\text { sin que dejéis hasta un tapiz tan solo. } \\
\text { A mí, señor! }\end{array}$ \\
\hline $\begin{array}{l}\text { NERÓN } \\
\text { PALANTE }\end{array}$ & $\begin{array}{l}\text { A ti. } \\
\text { ¿Por qué? }\end{array}$ \\
\hline NERÓN & $\begin{array}{l}\text { Por rico. } \\
\text { ¿No sabes tú que están siempre sujetos } \\
\text { a un golpe del ladrón o del tirano? }\end{array}$ \\
\hline PALANTE & ¡Señor!... \\
\hline NERÓN & Llevalde; muera. \\
\hline PALANTE & ¡Qué buen pago! \\
\hline NERÓN & Agora que estás gordo, es bien que sea. \\
\hline $\begin{array}{l}\text { PALANTE } \\
\text { NERÓN }\end{array}$ & ¡Ay, tirano cruel! \\
\hline NERÓN & ¡Ay, mi Popea! \\
\hline
\end{tabular}

Y con esto concluye el acto segundo.

La jornada tercera.

Por el diálogo de Fulgencio y Calixto nos enteramos, al comienzo de esta tercera jornada, de las nuevas maldades de Nerón: que ha apartado del gobierno a su preceptor el filósofo Séneca, que ha matado a cinco mil cristianos y a pocos menos gentiles, que tiene presos a San Pedro y a San Pablo... Fulgencio hace una pormenorizada y lujosa descripción de la vida que lleva Nerón y del fasto pagano que lo rodea:

A Publio Sila en Francia ha degollado, y a Plauto, capitanes como Aquiles; en músicas y fiestas ocupado, juegos y danzas y ejercicios viles, 
representa tragedias, y hace en ellas que entren hermosos mozos y doncellas.

Su casa desde el monte Palatino al Esquilino llega, que es distancia como de media legua de camino: edificio de altísima arrogancia. El licor de las fuentes cristalino es agua de odorífera fragancia; los estanques [son agua] del mar, que muda a veces para criar y para ver sus peces.

Las huertas frutüosas y jardines de mil cuadros floríferos esmalta, cuyos márgenes verdes y confines guarda una cerca defendida y alta. Allí corren las cabras mallorquines, el búfalo se tiende, el ciervo salta, y en las jaulas de patios y leoneras, los osos, tigres, onzas y panteras.

Las piezas de las salas, fabricadas de jaspes, mármol, pórfido y topacio, envidia el sol, y las de Oriente amadas deja para salir deste palacio.

Las techumbres y bóvedas doradas se van moviendo con el mismo espacio que el cielo, con sus orbes semejantes, sus eclipses, crecientes y menguantes.

Por alambiques de marfil y oro caen a tiempo flores y aguas puras; tiene baños labrados, que un tesoro cuestan sus aromáticas mixturas: aquí el infame, sin Real decoro, goza mil deleites y blanduras; aquí se afeita, lava y entretiene.

Nerón, según refiere ahora Niceto, extrema su crueldad con los cristianos:

Ayer hizo vestir a seis cristianos pieles de osos y ciervos fugitivos, y echarles perros turcos y britanos, que así a pedazos los comiesen vivos; y los sabuesos rígidos y alanos no se mostraron a la caza esquivos, porque los tiene hambrientos para esto.

(p. 105)

Cuando Nerón descubre una conspiración contra él -el pueblo romano se conoce que ya se va hartando de tanta gratuita crueldad y, por supuesto, el final del drama se va acercando y Lope desea irlo preparando-, que poco antes ha decretado ya la muerte de Otavia, ordena la matanza de quinientos hombres. Y 
cuando Félix le pregunta, se ve que algo incrédulo, «¿A quinientos hombres?», el tirano responde:

Sí;

a quinientos, a ochocientos, a dos mil, a dos millones, al mundo, a los elementos, y al cielo, si al cielo pones en tan bajos pensamientos.

(p. 111)

¿Quedaba alguien a quien matar? Sí, Séneca, que todavía anda vivo, aunque postergado. Pues ahora le toca a él. Y es Nerón en persona quien le comunica su mortífero deseo al propio filósofo, a quien negándole toda clemencia o sombra de piedad, tan sólo le da a elegir el medio: «Toma cordel o veneno,/ o acero, si éste no es bueno; que esto sólo haré por ti». Desde luego, este Nerón es un monstruo, una verdadera enciplopedia de maldades. Y él mismo parece jactarse de ello:

¿Cómo no tiembla quien mira

mi rostro bañado en ira?

Yo soy el que abraso el suelo, yo soy los rayos del cielo;

que los otros son mentira.

¿Qué me detiene y repara?

Para muerte, yo bastara.

¡Ojalá en esta fiereza

fuera Roma una cabeza;

que de un golpe la cortara!

(p. 112)

La de Otavia era una muerte anunciada, y ahora se cumple. Muerte alevosa, por cierto, ya que perece acusada - Otavia, modelo de castidad- de adulterio. Pero, puestos a cometer desatinos y crueldades, la más notable, sin duda, de las de Nerón fue el incendio de Roma. Y aquí nos lo presenta ya Lope, supuesto que no podía faltar (y nótese, de paso, el efecto cómico de la rima):

Enciéndase luego:

echad fuego en toda Roma;

que mañana, antes que coma, no habrá Roma.

(p. 114)

Pero el descontento de los romanos crece, como es natural, y sigue ahora una escena en la que, según indica la acotación: «Salen con una caja y bandera soldados romanos y Furio, y Galba detrás con laurel y bastón y un papel». Examinan el haz y el envés del imperio de Nerón. Furio se pregunta:

¿Posible es que un mancebo generoso, enseñado de Séneca, haya muerto 
cien mil hombres romanos en seis años, por envidia los más, y sin delitos?

Y Galba explica así las razones de la permanencia en el poder de tan monstruoso tirano:
Mas es su poder tanto, y tiene al vulgo
y a la gente de guerra tan contenta
con los repartimientos y los gastos, con fiestas y con vicios consentidos, que estima su salud con más lisonjas que si fuera el divino Otavïano.

La rebelión ya está en marcha, y los soldados aclaman a Galba por Emperador. Tras de ello, vemos a «Nerón, Popea, Niceto y Fenicio en una torre desde la cual se ve a Roma ardiendo». Es aquí donde, «tañendo y cantando» los personajes, inserta Lope su recreación de un viejo romance, que aparecía ya en $\mathrm{LaCe}$ lestina: «Mira Nero de Tarpeya/ a Roma cómo se ardía:/ gritos dan niños y viejos,/ y él de nada se dolía» ${ }^{5}$. Y mientras Nerón y sus compinches contemplan el incendio de Roma, un grupo de senadores trata de cómo se ha de poner fin a la aborrecible tiranía. Vitelio, uno de ellos, comunica a los demás que las legiones se han alzado en distintos puntos del imperio. Los senadores se juramentan para dar muerte a Nerón.

Este, por lo demás, sigue haciendo de las suyas. Cuando Popea le enfada con celos por cierto billete que ha llegado a manos de Nerón, este - genio y figura hasta la sepultura - la revienta a patadas, a pesar de que está embarazada:

\begin{tabular}{|c|c|}
\hline POPEA & Paso, paso... \\
\hline & ¡Mira que preñada estoy! \\
\hline NERÓN & $\begin{array}{l}\text { Por dos coces que te doy } \\
\text { no temo siniestro caso, } \\
\text { y tú debes hablar bien, } \\
\text { sin fiarte en que te adoro. }\end{array}$ \\
\hline
\end{tabular}

Después de haber muerto a su coima, y al hijo que ésta llevaba en sus entrañas, el final, por fin, se precipita. Comunican a Nerón que el Senado le busca para asesinarle. Ante la imposibilidad manifiesta de resistir, huye. Se refugia en casa de un labrador, pero éste no quiere darle asilo, por no comprometerse. Así que no tiene más remedio que poner fin a su vida con sus propias manos. Este es el fin de Nerón:

¡Qué miedo tengo al acero!

¡Pese a Júpiter y a Marte!

¡Oh vida, a los hombres cara,

5 En el Acto I, en boca de Sempronio: cfr. E. Berndt Kelley, «Popularidad del romance Mira Nero de Tarpeya», en Estudios dedicados a James Homer Herriott, Madison, 1966, pp. 117-126. 
y cuánto el perderte altera!

¿Esto es morir? Cosa es clara

que, si su pena supiera, nunca yo a tantos matara.

¿Quiere alguno de los dos

matarse?

(p.121-122)

Y le contestan, tono bufo hasta el final, para desmentir el tono de tragedia o de seriedad dramática: «¡Bueno, por Dios! / ¡Ved con lo que nos convida!» y, ya clavada la daga ${ }^{6}$ en el pecho neroniano, uno de los presentes apostilla con este glorioso comentario: «iQué cara ha puesto tan fea!» ${ }^{7}$.

Llega el pueblo romano y encuentran a Nerón muerto. Proclaman a Galba Emperador. Y Sulpicio pone fin a la representación:

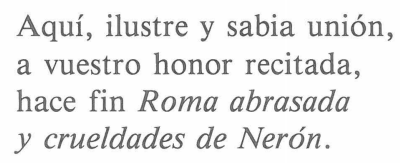

El abigarrado y bullicioso público del corral debió de pasar un buen rato.

\section{Conclusiones: Lope, entre paraliteratura y parodia.}

Roma abrasada, por lo que hemos leído, cabe muy escasamente en los moldes de la tragedia. O más exactamente: no es, en absoluto, una tragedia. Roma abrasada es un magnífico ejemplo de comedia divertida, donde se muestra a un malo malísimo, Nerón, pero con más intención de parodia que de tragedia. Sus personajes no son tales, sino marionetas de guiñol, que intercambian asesinatos, crueldades e infamias como si fueran palos de títere. Los espectadores de la $R O$ ma abrasada debieron de pasar en efecto, un buen rato de diversión, pues todos los ingredientes para el pasatiempo están servidos en la pieza de Lope: lujo; sangre; sexo; morbo; elementos que el público podía fácilmente reconocer, como el romancero; tópicos y lugares comunes que confirmarían las ideas del vulgo, como el justo castigo del culpable, etc... Roma abrasada debió de ser una de tantas comedias rápidamente fabricadas para el consumo de la «industria» teatral de la época, en tantos aspectos comparable al fenómeno cinematográfico de nuestros días, un arte doblado de industria, y viceversa. Como pasatiempo, pues, nada habría que objetar a esta «película de romanos» escrita por Lope. Pero no

6 No deja de ser curiosa la nota de D. Juan Eugenio Hartzembusch: «La nota de la edición antigua dice: 'Métase aquella daga de la invención de Bárbara'. Alude, sin duda, a la famosa actriz Bárbara Coronel. La tal daga sería como los cuchillos o puñales de que se hace uso en los juegos de manos: instrumento sin punta, en que la hoja, cuando es preciso, se entra y oculta en el mango».

7 En su estudio sobre la obra, Menéndez Pelayo, insistiendo en su visión de la obra como parodia, comenta en nota: «¿Qué mayor burla que esta reflexión de un labrador, después que Nerón se mata? ¡Notable final de tragedia!» (Estudios sobre el teatro de Lope de Vega, Madrid, CSIC, 1949, t. II, p. 297). 
se trata, evidentemente, de una tragedia. En este sentido, concordamos con el certero juicio de Menéndez Pelayo:

«Obra de irregular y monstruosa estructura, sin ningún género de enlace interno entre sus escenas, que se suceden con la misma rapidez que las vistas de un estereoscopio [...] Es una pieza de teatro de muñecos, en que Lope parece burlarse del asunto, amontonando con el mayor desorden los más complicados y heterogéneos incidentes, y mezclando en abigarrado tropel los personajes más disímiles, resultando de todo ello una especie de mascarada poética, que, con ser tan absurda, divierte por lo que tiene de parodia. La rapidez desaforada de la acción, y la mezcolanza de costumbres antiguas y modernas, contribuyen al efecto cómico de ésta, que, con llamarse tragedia, es una de las cosas menos trágicas del mundo, a pesar de los horrores que en ella se acumulan» ${ }^{8}$.

¿Por qué entonces la denominó tragedia su autor? Es posible que en esta obra temprana ${ }^{9}$, Lope estuviese todavía muy cerca de la influencia del teatro trágico senequista español, en el que destacaron Juan de la Cueva o Cristóbal de Virués, este último reconocido explícitamente por Lope como maestro ${ }^{10}$. Este teatro neosenequista llega a los españoles no directamente, sino a través de modelos italianos ${ }^{11}$, y domina la producción trágica del XVI con su desfile de horrores, crueldades, asesinatos y derramamiento de sangre. Resulta muy significativo que uno de estos trágicos, Lupercio Leonardo de Argensola, nos presente la tragedia como una obra en la «que todo ha de ser llanto, muertes, guerras,/ envidias, inclemencias y rigores» ${ }^{12}$. De hecho, y como acertadamente escribe Otis H. Green, Argensola concibe la tragedia como «una serie de hechos sangrientos, todos ellos encaminados ostensiblemente a mostrar que el pecado termina en la muerte» ${ }^{13}$. Juan de la Cueva, otro de estos trágicos, se adhiere al criterio muy extendido entonces de considerar tragedia la obra teatral con final desgraciado: un claro ejemplo de ello lo tenemos en su Tragedia del príncipe tirano ${ }^{14}$, que es en realidad la segunda parte de la comedia del mismo título. A la primera parte la llamó «comedia», porque el príncipe conservaba su vida en la escena final; a la segunda la denominó «tragedia» porque moría a manos de dos mujeres a las que pretendía forzar. Resulta sumamente curioso que el juicio que formula un crítico de hoy sobre esta pieza de Cueva se pudiera aplicar sin apenas variación a la Roma abrasada:

8 Ibíd., pp. 297-298.

9 Publicada por ver primera en la Parte $X X$ (Madrid, 1625), Morley y Bruerton la datan hacia 1598-1600 (Cronología de las comedias de Lope de Vega, Madrid, Gredos, 1968, pp. 390-391).

10 K. A. Blüher propone La gran Semíramis, de Virués, como el modelo efectivo seguido por Lope en su Roma abrasada (vid. «Lope de Vega y Séneca: A propósito de la tragedia Roma abrasada, art. cit.).

11 Cfr. Karl Alfred Blüher, Séneca en España, Madrid, Gredos, 1983, pp. 318-330.

12 «Loa» a su tragedia Alejandra, tomo la cita de F. Sánchez Escribano y A. Porqueras Mayo, Preceptiva dramática española del Renacimiento y el Barroco, Madrid, Gredos, 1972, 2a ed. muy ampliada, p. 69.

13 Vida y obras de Lupercio Leonardo de Argensola, trad. de F. Ynduráin, Zaragoza, Institución «Fernando el Católico», 1945, p. 103.

14 En Comedias y Tragedias, Madrid, Sociedad de Bibliófilos Españoles, 1917, 2 vols. 
«La pieza tiene muchos defectos: exceso de acción; exceso de brutalidad y de tiranía en el protagonista; exceso de locura; la escena del enterramiento de los familiares de Teodosia y Doriclea, en el último acto, es ridícula; muchos personajes mueren sin motivo, etc... Junto a esto, encontramos una versificación fluída en ocasiones, y unos caracteres bien retratados en su monstruosa inverosimilitud $»^{15}$.

La fecha temprana de la comedia (comedia en sentido amplio de pieza teatral) de Lope permite situarla - como hace W. Ruser ${ }^{16}$ - en el terreno de influencia de estos trágicos neo-senequistas. Pero la imitación neo-senequista vía Virués, Argensola, Cueva, etc... no la hace Lope completamente en serio: se observa un claro distanciamiento irónico, o, por mejor decir, paródico, por parte del autor del Arte nuevo de hacer comedias. Esta aparente contradicción no se logra explicar del todo si no tenemos en cuenta la creciente demanda de los corrales, a la que Lope tiene que satisfacer echando mano de materiales y asuntos muy diversos, con una rapidez y un sistema de producción verdaderamente más propio de la cultura de masas, de la industria subcultural, que de la Alta Cultura. No es extraño así que muchas de sus obras, más que ser tragedias, o comedias, o tragicomedias, resulten productos paraliterarios y, en muchos casos, subliterarios ${ }^{17}$. Es el caso, nos parece, de Roma abrasada, pieza en la que Lope se ha limitado a poner en versos hilvanados con una mínima armazón teatral (y teatral, en efecto, más que dramática) la crónica que del tirano Nerón le ofrecía la Historia Imperial y Cesárea (1545) de Pedro Mexía ${ }^{18}$. Estamos, pues, básicamente de acuerdo con W. Ruser, que achaca a la pieza falta de hilo argumental y exceso de incidentes y personajes, cuando concluye: «Im Grossen und Ganzen haben wir Kein Drama, sondern insznierten historischen Bericht vor uns» ${ }^{19}$. Y en efecto, la Roma abrasada no es sino un relato histórico dramatizado, de nivel paraliterario, urdido como pieza de pane lucrando, a la que es imposible tomar en serio como tragedia ${ }^{20}$, denominación que sólo se explica por la cercana influencia del

15 A. Hermenegildo, Los trágicos españoles del siglo XVI, Madrid, Fundación Universitaria Española, 1961, p. 325 .

16 «Roma abrasada, ein echtes Jugenddrama: eine Studie zu Lope de Vega», en Revue Hispanique, LXXII (1928), pp. 325-411.

17 Véase para esto nuestro artículo «Literatura y paraliteratura en el teatro de Lope...», citado.

18 Es la fuente apuntada por Menéndez Pelayo, y generalmente aceptada desde entonces; vid., en relación con esto, el artículo de D. Tarancón y García, «Sobre técnicas de utilización de las fuentes en la Roma abrasada de Lope», en Fénix, I, 1935, pp. 363-93.

19 «Roma abrasada, ein echtes Jugenddrama...», cit., p. 408.

20 Como hacía D. Agustín Montiano y Luyando, quien en su Discurso sobre las tragedias españolas (Madrid, Imprenta de Mercurio, 1750) estampaba este juicio: «Roma abrasada, es una menuda historia de Nerón, comenzando en vida de Claudio, y acabando en la muerte del mismo Nerón: cuyos cinco años de imperio piadoso, se acuerdan con puntual noticia de lo que escribe Séneca en su libro de Clemencia (sic), a costa de representarse una escena en Armenia, entre Volgesio, Rey de los Parthos, y Dardanio su hermano. La misma dislocación de la unidad de lugar se comete en otra escena puesta en España, para la sublevación de Galba; y según la serie de toda la obra, sólo la caracteriza la quema de Roma; por ser una de las últimas crueldades de este tirano príncipe, y en algún modo la más famosa. No me extiendo a otros reparos; porque bastan los que adjunto, a dar una idea de lo que es, la que llama Lope tragedia». (pp. 50-51). 
teatro neo-senequista de los trágicos españoles del XVI, del que toma ciertas características pero, para que la pieza «funcione» en el corral de comedias, con guiños constantes al espectador para que este ría y se lo pase bien oyendo las monstruosidades del tirano Nerón, el que andaba en coplas, dichos y romances. Lope se halla todavía muy lejos de cobrar plena y suficiente conciencia del valor estético de su teatro, y de la posibilidad de una tragedia nueva dentro de éste, que de modo explícito no formulará hasta 1635 , en la célebre dedicatoria de su tragedia - esta sí- El castigo sin venganza ${ }^{21}$.

21 «Esta tragedia — declaraba allí Lope, como se sabe- está escrita al estilo español, no por la antigüedad griega y severidad latina...» Cfr. Lope de Vega, El castigo sin venganza, edición crítica de José María Díez Borque, Madrid, Espasa-Calpe, 1988, col. Clásicos castellanos. Nueva Serie. Véase ahora también un interesante conjunto de estudios sobre esta tragedia en Ricardo Domenech (ed.), «El castigo sin venganza» y el teatro de Lope de Vega, Madrid, Cátedra-Teatro Español, 1987. 
